\title{
Bone density in asthmatic patients taking high dose inhaled beclomethasone dipropionate and intermittent systemic corticosteroids
}

\author{
G E Packe, J G Douglas, A F McDonald, S P Robins, D M Reid
}

\begin{abstract}
Background Asthmatic patients taking low to moderate doses of inhaled topical corticosteroids have been shown to have lower bone density than those taking bronchodilators only. There is little information on bone density in asthmatic patients taking high dose inhaled corticosteroids.

Methods Bone mass was studied in three age matched groups of asthmatic patients. These comprised: 17 asthmatic patients who had never taken inhaled or systemic corticosterotds (group -1); 20 patients who had taken beclomethasone dipropionate in a dosage of $1000=2000 \mu \mathrm{g}$ daily for at least a year, who had also received courses of systemic corticosteroids in the past (group 2); and 20 patients who were taking both high dose inhaled corticosteroids and regular low dose prednisotone, at a median dose of 7 mg daily (group 3). Vertebral bone density was measured by quantitative computed tomography. Biochemical indices of bone formation and resorption were also measured.
\end{abstract}

Results Mean bone density in group 2 $(127.5(22.6) \mathrm{mg} / \mathrm{ml})$ was similar to that in group $3(114.5(36.0) \mathrm{mg} / \mathrm{ml})$. Bone density was significantly lower in both of these groups than in group $1(160.4(27 \cdot 4)$ $\mathrm{mg} / \mathrm{ml}$ ). There were no significant differences between groups for any of the markers of bone formation and resorption.

Conclusions Asthmatic patients receiving high dose inhaled beclomethasone and intermittent courses of systemic corticosteroids have reduced vertebral bone density. The bone loss is similar in degree to that seen in patients taking high dose inhaled topical corticosteroids and continuous low ase systemic corticosteroids.

$$
\rightarrow
$$

Systemic corticosteroids are effective in the treatment of asthma but their long term use is associated with bone loss. ${ }^{1}$ The action of corticosteroids on bone is complex; they probably both inhibit bone formation and accelerate bone resorption via several mechanisms. ${ }^{2}$ The bone loss occurs mainly at sites in the skeleton where there is a high concentration of corticosteroid in trabecular bone, such as the spine and ribs. ${ }^{3}$
Treatment with inhaled topical corticosteroids has been a major advance in the treatment of asthma, permitting effective control of symptoms without the serious side effects associated with systemic corticosteroids. It has become apparent, however, that inhaled topical corticosteroids may have an adverse effect on bone. In a previous study in patients with mid and moderate asthma taking beclomethasone dipropionate $400 \mu \mathrm{g}$ daily, or an equivalent dose of inhaled betamethasone, the total calcium content was shown to be $8.8 \%$ lower than in asthmatic patients not taking either inhaled or systemic corticosteroids. ${ }^{4}$

The efficacy of inhaled corticosteroids in treating asthma is dose dependent so that by increasing the dosage patients with more severe asthma can be kept in remission. ${ }^{5}$

The aim of the present study was to investigate trabecular bone density in patients taking high dose inhaled beclomethasone dipropionate.

\section{Methods}

PATIENTS

We studied 57 asthmatic patients ( 30 male, 27 female), attending either their general practitioner or a hospital clinic, at two hospital visits within one week. None had had their regular treatment adjusted within the past year. All the female patients were premenopausal. None reported recent bone fractures or suffered from metabolic bone disease.

Patients were divided into three groups, details of which are given in table 1 . The 17 patients in group 1 were attending their general practitioner with mild asthma, requiring only bronchodilators for relief of symptoms. None had ever required inhaled or oral corticosteroids."

The 20 subjects in group 2 were taking regular high dose inhaled beclomethasone dipropionate in a dose ranging from 1000 to $2000 \mu \mathrm{g}$. All had been taking high dose beclomethasone for more than a year (median duration three (range 1-7) years). None had ever taken regular oral corticosteroids, but all had needed short courses of oral corticosteroids in the past for exacerbations; 10 patients had received oral prednisolone within the past year whereas the remainder of the group had not. The total cumulative dose of prednisolone these patients had taken could not be determined accurately; some had received this 
Table 1 Details of asthmatic patients

\begin{tabular}{clll}
\hline & & $\begin{array}{l}\text { Group 2 } \\
\text { (inhaled and } \\
\text { intermittent } \\
\text { systemic } \\
\text { steroids) }\end{array}$ & $\begin{array}{l}\text { Group 3 } \\
\text { (inhaled and } \\
\text { continuous } \\
\text { systemic } \\
\text { steroids) }\end{array}$ \\
\hline $\begin{array}{c}\text { No steroids) } \\
\text { Sex ratio } \\
\text { (M:F) } \\
\begin{array}{c}\text { Mean (SD) } \\
\text { age (y) }\end{array}\end{array}$ & 17 & 20 & 20 \\
\hline
\end{tabular}

treatment as hospital inpatients or outpatients, others had been prescribed courses by their general practitioner or had initiated such treatment themselves. A recently introduced computerised follow up system, however, allowed an accurate assessment of the number of courses of corticosteroids patients had received during the previous year. Twelve patients used a spacer device attached to their inhaler and the remainder used the inhaler alone. All were regularly attending hospital clinics.

The 20 patients in group 3 were attending hospital clinics with asthma and needed daily oral prednisolone in a median dosage of 7 (range 5-30) $\mathrm{mg}$, which they had been taking for a median of 8 (range 1-25) years. They had also intermittently required courses of high dose systemic corticosteroids, and had taken regular high dose inhaled topical corticosteroids for a median of five (range 1-7) years.

Informed consent was obtained from all patients and approval for the study was given by the local ethical committee.

\section{BONE METABOLISM AND DENSITY}

Indices of bone metabolism were measured in all patients. A morning sample of serum was collected for measurement of serum calcium, total alkaline phosphatase, and osteocalcin. ${ }^{6}$ The latter two are markers of bone formation. A fasting urine sample was analysed for pyridinoline and deoxypyridinoline cross links ${ }^{7}$; both give a measure of collagen breakdown, the latter being a more specific index for collagen breakdown in bone. ${ }^{8}$

Table 2 Data on bone metabolism (mean (SD) or median (range) values)

\begin{tabular}{|c|c|c|c|}
\hline & $\begin{array}{l}\text { Group } 1 \\
\text { (no steroids) }\end{array}$ & $\begin{array}{l}\text { Group } 2 \\
\text { (inhaled and } \\
\text { intermittent } \\
\text { systemic } \\
\text { steroids) }\end{array}$ & $\begin{array}{l}\text { Group } 3 \\
\text { (inhaled and } \\
\text { continuous } \\
\text { systemic } \\
\text { steroids) }\end{array}$ \\
\hline $\begin{array}{l}\text { Bone density (mg/ml) } \\
\text { Serum calcium (mmol/l) } \\
\text { Serum alkaline phosphatase (IU) } \\
\text { Serum osteocalcin (mg/ml) } \\
\text { Urinary pyridinoline }\end{array}$ & $\begin{array}{c}160 \cdot 4(27 \cdot 4) \\
2 \cdot 31(0 \cdot 16) \\
61 \cdot 3(17 \cdot 6) \\
9 \cdot 3(2 \cdot 9)\end{array}$ & $\begin{array}{c}127.5(22.6)^{\star \star} \\
2.43(0.13) \\
68.9(14.4) \\
9.0(2.2)\end{array}$ & $\begin{array}{c}114.5(36.0) \\
2.46(0.14) \\
67.5(17.4) \\
8.6(3.4)\end{array}$ \\
\hline $\begin{array}{l}\text { (nmol/mmol creatinine) } \\
\text { Urinary deoxypyridinoline }\end{array}$ & $35 \cdot 0(20 \cdot 1-87 \cdot 9)$ & $32 \cdot 0(17 \cdot 9-50 \cdot 8)$ & $34.9(16.4-205 \cdot 3)$ \\
\hline $\begin{array}{l}\text { (nmol/mmol creatinine) } \\
\text { FEV } 1 \text { (l) } \\
\text { Activity grade }\end{array}$ & $\begin{array}{l}8 \cdot 3(3 \cdot 9-19 \cdot 8) \\
3 \cdot 34(1 \cdot 00) \\
4(2-4)\end{array}$ & $\begin{array}{l}8 \cdot 3(4 \cdot 1-13 \cdot 8) \\
2 \cdot 62(1 \cdot 14)^{\star} \\
4(1-4)\end{array}$ & $\begin{array}{l}8.9(3.3-37.3) \\
1.86(0.53)^{\star} \\
3.5(2-4)\end{array}$ \\
\hline
\end{tabular}

${ }^{\star} \mathrm{p}<0.05 ;{ }^{\star} \mathrm{p}<0.001$ (comparisons between groups 1 and 2 and between groups 2 and 3 by Student's $t$ test or the Mann-Whitney $U$ test as appropriate).
Trabecular bone density was measured by quantitative single energy computed tomography of the lumbar spine. ${ }^{9}$ The average value for bone density of lumbar vertebrae L $1-3$ was calculated and expressed in $\mathrm{mg} / \mathrm{ml}$. These average values were also expressed as standard deviations above or below the predicted mean value (derived from values for a normal popula$\left.\operatorname{tion}^{10}\right)$. The precision of the technique was assessed by performing duplicate measurements on 10 normal subjects, which gave a coefficient of variation of $0.98 \%$. Bone density evaluation and the measurement of indices of bone turnover in serum and urine were carried out without knowledge of the group to which the patient belonged.

\section{ACTIVITY OF PATIENTS}

Patients' level of activity at work and during recreation was assessed by means of a simple scale of hours of activity per week, where activity was defined as anything that more than doubled the basal metabolic rate (grade 1-less than 1 hour; grade 2-1-3 hours; grade 3-3-6 hours; grade 4 -more than 6 hours. ${ }^{11}$

\section{ANALYSIS}

Differences between groups were compared by using Student's $t$ test for normally distributed data and the Mann-Whitney $U$ test for nonparametric data. The association between bone density and the duration of steroid treatment was assessed by regression analysis.

\section{Results}

Bone density, indices of bone turnover, $\mathrm{FEV}_{1}$ and the level of activity for the patients in the three groups are shown in table 2 . Mean bone densities were significantly lower in groups 2 and 3 ( $p<0.001$ ) than in group 1 ; there was no difference between groups 2 and 3 . Bone density results are also shown in the figure, expressed in terms of standard deviation above or below the predicted normal values for subjects of the same age and sex.

Mean $\mathrm{FEV}_{1}$ was significantly lower $(\mathrm{p}<0.05)$ in group 2 than in group 1 , and lower in group 3 than in group $1(p<0.05)$. The level of activity at work and during recreation was similar across the three groups.

Among the 20 patients in group 2 there was no difference in bone density between the 10 patients who had received oral corticosteroids during the past year and the 10 patients who had not (figure). Similarly, there was no difference between the 12 patients who were taking their inhaled corticosteroids through a spacer device and those who were not. There was no relation between the duration of treatment with high dose inhaled corticosteroids and bone density.

Serum calcium and total alkaline phosphatase, serum osteocalcin, and urinary pyridinium cross links were similar in the three groups of patients.

All patients with bone densities more than two SD below the predicted values were referred to a clinic specialising in the treatment of osteopenia and osteoporosis. 


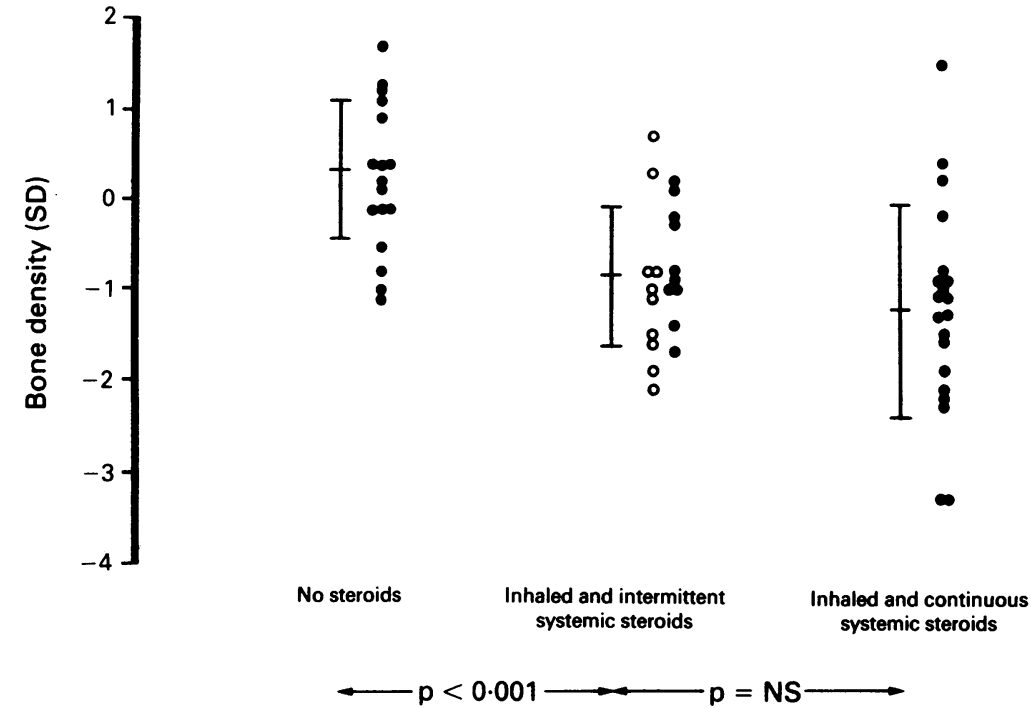

Bone density in three groups of asthmatic patients expressed as standard deviation above or below the predicted mean value for age and sex. Horizontal bars indicate mean values and vertical bars SD. O-Those patients taking high dose inhaled steroids who had not taken systemic corticosteroids over the past year.

\section{Discussion}

This study has shown that patients in group 2 , taking beclomethasone dipropionate in a dose of $1000 \mu \mathrm{g}$ or more and intermittent systemic corticosteroids, had significantly more bone loss than asthmatic patients in group 1 not inhaling corticosteroids. Moreover, the-magnitude of bone loss in patients in group 2 was similar to that seen in pattents in group 3 , who were taking inhaled corticosteroids and continuous low dose systemic corticosteroids.

It was not possible, however, to determine whether the reduced bone density in patients in group 2 was due to high dose beclomethasone or due to the effect of previous booster courses of systemic corticosteroids. We were unable to identify any patients who were taking high dose beclomethasone who had never received systemic corticosteroids. An earlier study, in which Reid et $a l^{4}$ suggested that reduced bone mineral content in patients with asthma was a consequence of the effects of moderate dosages of inhaled corticosteroids, was criticised because the possible effect of booster courses of oral prednisolone that these patients had taken was not fully taken into account. ${ }^{12}$

Nevertheless, three recent studies in nonasthmatic subjects have shown that beclomethasone dipropionate has the potential to exert deleterious effects on bone. Twelve individuals taking $2000 \mu \mathrm{g}$ of beclomethasone for four weeks showed an increase in bone breakdown (increased urinary hydroxyproline: creatinine ratio) and a reduction in bone formation (reduced serum alkaline phosphatase). ${ }^{13}$ Pouw et al studied eight healthy subjects who also took beclomethasone $2000 \mu \mathrm{g}$ a day for two weeks: osteocalcin concentrations fell significantly during the treatment phase but fully recovered one week after the beclomethasone was stopped. ${ }^{14}$ Teelucksingh et al found a fall in osteocalcin concentrations in healthy subjects taking beclomethasone in daily doses of 400-2000 $\mu \mathrm{g}$; the magnitude of the fall was dose dependent. ${ }^{15}$

In the present study indices of bone turnover, including osteocalcin concentration, were the same in all three groups, implying that bone loss had occurred at some time in the past. This may have occurred when patients were initially started on high dose beclomethasone; after some months bone formation and bone breakdown could have returned to pretreatment levels, but because there was no compensatory increase in bone formation or reduction in bone loss bone density remained low. In patients taking systemic corticosteroids bone loss is most rapid during the first few months of treatment. ${ }^{2}$

Alternatively, the bone loss in the patients taking beclomethasone may have occurred predominantly at times when they were having courses of high dose oral corticosteroids. Although the propensity of continuous systemic corticosteroid treatment for causing osteoporosis is well established, ${ }^{2}$ there is less information on the effect of intermittent treatment. Adinoff' ${ }^{1}$ showed a slightly lower trabecular bone density in 11 asthmatic patients taking intermittent oral corticosteroids (without inhaled corticosteroids) than in normal controls, whereas 19 asthmatic patients taking continuous oral corticosteroids had a significant reduction in bone density. In the present study there was no difference in bone density between those patients in group 2 who had received booster courses of prednisolone within the past year and those who had not, which lends some weight to the argument that bone loss in this group was associated with high dose inhaled beclomethasone rather than with courses of prednisolone.

Further prospective studies are needed to clarify the role of high dose inhaled beclomethasone and booster courses of corticosteroids in altering bone turnover in asthma.

Bone density in groups 2 and 3 in the present study was significantly reduced. How do these results relate to the risk of future fracture? Bone density in the patients taking high dose beclomethasone was reduced by a mean value of $0.84(0.77)$ SD below the predicted normal value for the patients' age and sex. The absolute value for bone density in these 20 patients was $127.5(22.6) \mathrm{mg} / \mathrm{ml}$. Although the risk of bone fracture is governed by the interaction of several factors, bone mineral density is an important predictor of fracture risk. On the basis of bone density in a cohort of postmenopausal women Ross et $\mathrm{al}^{16}$ have proposed a fracture threshold, at which the absolute risk of fracture is $0.5 \%$ a year, defined according to bone mineral density measured at various sites. They calculated that the vertebral bone density corresponding to this threshold was $97 \mathrm{mg} / \mathrm{ml}$. The average risk of fracture in patients taking high dose inhaled beclomethasone in the present study would therefore be expected to be low, only one of the patients in group 2 having a bone mineral density below this level. Eight of the 20 patients in group 3, however, had absolute bone densities below this level. In the study of Adinoff $e t$ al $^{1}$ mean trabecular bone 
density in a group of asthmatic patients taking continuous oral corticosteroids, similar in age to those in the present study, was reduced by about $1.5 \mathrm{SD}$, and $11 \%$ of these patients had sustained fractures.

There was no difference in bone density between those patients in group 2 who had a spacer device to use with their beclomethasone inhaler and those who did not. The use of a spacer is thought to reduce systemic absorption of beclomethasone ${ }^{1 /}$ and would therefore be expected to minimise any adverse effect beclomethasone has on bone. In some of our patients the spacer had been introduced some time after they had been started on treatment with beclomethasone. Additionalty there was some doubt about whether those who had a spacer were using it regularly.

High dose inhaled beclomethasone dipropionate will continue to have a central role in treating patients with severe asthma; it may, however, be associated with an increased rate of bone loss. The dose should therefore be kept to the minimum necessary to control a patent's asthma.

We thank Mrs M Orr, Mr A Duncan, and Mr P Nicol for technical assistance. DMR is supported in part by the Arthritis and Rheumatism Council.

1 Adinoff AD, Hollister JR. Steroid induced fractures and bone loss in patients with asthma. $N$ Engl $J$ Med 1983;309:265-8.

2 Reid DM. Corticosteroid-induced osteoporosis. In: Smith R, ed. Osteoporosis. London: Royal College of Physicians of London, 1990:99-117.
3 Baylink DJ. Glucocorticoid-induced osteoporosis. N Engl J Med 1983;309:306-8.

4 Reid DM, Nicoll JJ, Smith MA, Higgins B, Tothill P, Nuki G. Corticosteroids and bone mass in asthma: comparisons with rheumatoid arthritis and polymyalgia. $B M J$ with rheumatoid

5 Smith MJ, Hodson ME. High-dose beclomethasone inhaler in the treatment of asthma. Lancet 1983;1:265-9.

6 Egsmose C, Daugaard H, Lund B. Determination of bone Gla protein (osteocalcin) by enzyme-linked immunosorbent assay. Clin Chim Acta 1989;184:279-88.

7 Black D, Duncan A, Robins SP. Quantitative analysis of the pyridinium crosslinks of collagen in urine using ionpaired reversed-phase high-performance liquid chromatography. Annal Biochem 1988;169:197-303.

8 Robins SP, Black D, Paterson CR, Reid DM, Duncan A, Seibel MJ. Evaluation of urinary hydroxypyridinium crosslink measurements as resorption markers in metabolic bone density. Eur J Clin Invest (in press).

9 Kalender WA, Klotz E, Süß C. Vertebral bone mineral analysis: an integrated approach with CT. Radiology 1987;164:419-23.

10 Kalender WA, Felsenberg D, Louis O, Lopez P, Klotz E, Osteaux $M$, et al. Reference values for trabecular and cortical bone density in single and dual-energy quantitative computed tomography. Eur J Radiol 1989; quantitative

11 Makrides L, Heigenhauser GJ, McCartney N, Jones NL. Maximum short term exercise capacity in healthy subjects aged 15-70 years. Clin Sci 1985;69:197-205.

12 Crompton GK. Corticosteroids and bone mass in asthma. BMJ 1987;294:123.

13 Ali NJ, Capewell S, Ward MJ. Bone turnover during high dose inhaled corticosteroid therapy. Thorax 1991;46: $160-4$.

14 Pouw EP, Prummel MF, Ossting H, Roos CM, Endert E. Beclomethasone inhalation decreases serum osteocalcin concentrations. BMJ 1991:302:627-8.

15 Teelucksingh S, Padfield PL, Tibi L, Gough KJ, Holt PR. Inhaled corticosteroids, bone formation, and osteocalcin. Lancet $1991 ; 338: 60-1$.

16 Ross PD, Wasnich RD, Heilburn LK, Vogel JM. Definition of a spine fracture threshold based upon prospective fracture risk. Bone 1987;8:271-8.

17 Brown PH, Blundell G, Greening AP, Crompton GK. Do large volume spacer devices reduce the systemic effects of high dose inhaled corticosteroids? Thorax 1990;45:736-9. 